\title{
Can Bariatric or Metabolic Surgery Cure Type 2 Diabetes?
}

\author{
Gustavo P. S. Miguel, Perseu Carvalho, João Luiz Azevedo, \\ Murilo Hosken Júnior, Évelyn Zambrana, Otávio Azevedo and Isaac Abreu \\ Federal University of Espírito Santo/ Cassiano Antônio Moraes University Hospital \\ Brazil
}

\section{Introduction}

Obesity is a multifactorial disease that affects millions of people worldwide. It is the main independent risk factor for developing type 2 diabetes mellitus (T2DM).1,2 Most patients with T2DM and glucose intolerance (GI) are overweight, a condition known as diabesity.2,3 In patients with the most severe form of obesity, i.e. morbid obesity, the likelihood of developing diseases associated with obesity is increased.1,4

We currently know that bariatric surgery provides sustained weight loss and welldocumented remission of T2DM.5,6 Patients who undergo bariatric surgery show long-term reduced mortality ${ }^{7}$ from coronary artery disease, cancer and diabetes; 136 lives are saved per 10,000 surgical procedures performed. ${ }^{8}$ Bariatric surgery is a relatively safe procedure that is becoming increasingly well-accepted; in 2007, approximately 170,000 bariatric procedures were performed in the USA. ${ }^{6}$ Currently, bariatric surgery is the most effective choice of treatment of morbidly obese patients with diabetes. ${ }^{9}$

The surgical procedures that are currently performed to treat morbid obesity are divided into two main groups: gastric restrictive procedures and combination procedures; the latter combine gastric restriction and malabsorption. ${ }^{10}$ The roux-en-Y gastric bypass (RYGB) is the combination procedure most frequently performed,7,11 whereas sleeve gastrectomy (SG) is an emerging restrictive procedure.12 SG can be performed as the first of a two-stage operation in patients at high risk of death, ${ }^{13,14}$ or as a definitive surgical procedure. ${ }^{15}$ It has shown good results with regard to weight loss ${ }^{16}$ and glycemic control in various studies. ${ }^{6,14,16,17}$ The potential advantages of SG include lower probability of vitamin and mineral deficiencies because this procedure has no malabsorptive component; access to the entire intestinal tract; no need for a subcutaneous access port or adjustments; absence of dumping syndrome and lower probability of intestinal obstruction. In addition, SG can be performed in patients who have inflammatory bowel disease or who have undergone bowel surgery, and it can be easily converted into RYGB. ${ }^{12,15}$ Both SG and RYGB can be performed with or without the placement of a Silastic ${ }^{\circledR}$ ring. 18,19

The metabolic control achieved with bariatric procedures has been demonstrated and reproduced in various medical centers worldwide. ${ }^{6}$ Metabolic control can be achieved with gastric restrictive procedures such as vertical banded gastroplasty, ${ }^{5}$ adjustable gastric banding 20 and, more recently, SG. ${ }^{17}$ However, it has been shown that glucose homeostasis is 
affected by various intestinal mechanisms observed exclusively in procedures that include a malabsorptive element, ${ }^{21}$ such as RYGB.22-24

A systematic review of 22,094 cases of morbidly obese patients submitted to bariatric surgery has shown that resolution of $\mathrm{T} 2 \mathrm{DM}$ was achieved in $76.8 \%$ of the cases, improvement being achieved in $86 \%$ of cases. ${ }^{25}$ Among the criteria used to diagnose metabolic syndrome, fasting glucose levels ${ }^{26}$ are the first to return to normal in patients submitted to Silastic ${ }^{\circledR}$ ring gastric bypass (SRGB), a modification of the traditional RYGB which consists in adding a Silastic ${ }^{\circledR}$ ring to the gastric bypass operation. Normoglycemia after bariatric procedures, as well as diabesity itself, 27,28 is multifactorial.6,29,30 Normoglycemia is observed as a result of dietary control,20,21 decreased plasma levels of ghrelin, ${ }^{32}$ weight loss and reduction of body fat ${ }^{6}$, as well as of the release of gastrointestinal hormones that interfere with the function of pancreatic $\beta$ cells (incretins).23,24,33,34

To compare the weight loss of morbidly obese patients submitted to either a Silastic ${ }^{\circledR}$ ring sleeve gastrectomy (SRSG) or an SRGB, as well as to compare the effects of both procedures on glucose homeostasis in morbidly obese patients, our research group developed a study that will be better described ahead.

\section{Methods}

\subsection{Study protocol}

This was a non-randomized, prospective, controlled clinical study. It was approved by the Research Ethics Committee of the University Hospital of the Federal University of Espírito Santo, Brazil (protocol no. 049/06) and registered in clinicaltrials.gov, identifier NCT00873405. In order to homogenize the sample, we adopted the following inclusion criteria: female patients aged 20-60 years, with BMI 40-45 (inclusive), who agreed on giving written informed consent. The exclusion criteria adopted were secondary obesity, alcohol or drug use, severe psychiatric disorder, binge-eating of sweets and previous stomach or bowel surgery.

\subsection{Sample}

Sixty-five female patients were included in the present study. The patients had a mean age of 36.03 years, mean BMI of 42.47 and mean waist circumference of $119.62 \mathrm{~cm}$. Mean preoperative fasting glucose levels were $103.38 \mathrm{mg} / \mathrm{dL}$ (Table 1).

\begin{tabular}{cc}
\hline Variables & Mean, SD, minimum value, maximum \\
value
\end{tabular}

Table 1. Anthropometric data and preoperative fasting glucose levels.

The diagnoses of diabetes and GI were based on the criteria adopted by the Brazilian Diabetes Society. ${ }^{35}$ T2DM was found in 14 patients $(21,5 \%)$ and GI, a transitional state to diabetes itself, was found in 12 patients (18,5\%). Therefore, $40 \%$ of the morbidly obese patients analyzed in the present study presented with elevated fasting glucose levels (Table 2). 


\begin{tabular}{ccc}
\hline Fasting glucose levels & $\mathbf{n}$ & $\mathbf{0}$ \\
\hline Normal & 39 & $60 \%$ \\
Glucose intolerance & 12 & $18,5 \%$ \\
Diabetes & 14 & $21,5 \%$ \\
\hline
\end{tabular}

Table 2. Prevalence of preoperative type 2 diabetes mellitus and glucose intolerance.

Most of the diabetic patients used oral hypoglycemic agents (Table 3).

\begin{tabular}{ccc}
\hline Therapy & $\mathbf{n}$ & $\mathbf{0}$ \\
\hline Diet & 6 & $9 \%$ \\
OHG & 7 & $11 \%$ \\
OHG + Insulin & 1 & $2 \%$ \\
\hline
\end{tabular}

OHG - oral hypoglycemic agent

Table 3. Preoperative antidiabetic therapy.

The 65 patients were divided into two groups; 33 patients (51\%) were submitted to SRSG (SRSG group), whereas 32 (49\%) patients were submitted to SRGB (SRGB group). Assessment was performed again 12 to 14 months after the surgery.

\subsection{Surgical procedure}

The surgical procedures were performed between December 08, 2006 and July 27, 2007 at Hospital Universitário Cassiano Antonio Moraes from the Universidade Federal do Espírito Santo (HUCAM/UFES, Cassiano Antonio Moraes University Hospital, Federal University of Espírito Santo). The procedures were performed by the same surgeon using a similar anesthetic technique (peridural anesthesia combined with general anesthesia).

The patients from the SRSG group were submitted to the following procedures: ligation of the vessels of the greater curvature of the body and fundus of stomach; resection of the fundus and part of the body of stomach using a linear stapler $(80 \mathrm{~mm}$, Tycoß) and a 32-Fr tube to calibrate the remaining stomach; placement of a $6.2 \mathrm{~cm}$ Silastic ${ }^{\circledR}$ ring around the stomach, $5.0 \mathrm{~cm}$ below the esophagogastric junction.

The patients of the SRGB group were submitted to the following procedures: creation of a small, proximal gastric pouch and exclusion of a large part of the stomach using a linear stapler $\left(80 \mathrm{~mm}\right.$, Tyco $\left.{ }^{\circledR}\right)$ and a $32-\mathrm{Fr}$ tube to calibrate the gastric pouch; creation of an intestinal loop of $150 \mathrm{~cm}$ and a biliopancreatic loop of $40 \mathrm{~cm}$; placement of a $6.2 \mathrm{~cm}$ Silastic ${ }^{\circledR}$ ring around the stomach, $5.0 \mathrm{~cm}$ below the esophagogastric junction.

In both groups, the stapled lines were sutured and a methylene blue test was performed to verify whether the staple line was secure. The patients were given a liquid diet on the first postoperative day and were to be discharged on the third postoperative day. They received dietary guidance and instructions regarding physical activities. In addition, patients from both groups were prescribed similar vitamin and mineral supplementation.

\subsection{Assessment}

Weight loss, BMI reduction and waist circumference reduction were assessed. The percentage of excess BMI loss was calculated as follows: preoperative BMI - current BMI $\div$ preoperative BMI - $25 \times 100 .{ }^{36}$ Glucose homeostasis was assessed through the measurement of fasting glucose levels after the interruption of the pharmacological treatment. 


\subsection{Statistical analysis}

Descriptive analysis was conducted and the results were expressed as means, standard deviations, medians, frequency (\%), minimum values and maximum values. The MannWhitney test was applied to assess sample variation and homogeneity between groups. Fisher's exact test and chi-square test were employed to compare the results between the two groups. The ANOVA was used to assess glucose levels according to time and groups. Statistical significance was set at $\mathrm{p}<0.05$.

\subsection{Results}

In the preoperative period, no significant difference in age, BMI or waist circumference was found between patients from the SRSG group and patients from the SRGB group (Table 4).

\begin{tabular}{ccc}
\hline Variable & Group & $\begin{array}{c}\text { Mean, SD, minimum value, } \\
\text { maximum value* }^{*}\end{array}$ \\
\hline \multirow{2}{*}{ Age } & SRSG & $36.70 \pm 9.4(20-59)$ \\
& SRGB & $35.34 \pm 9.04(21-58)$ \\
BMI & SRSG & $42.33 \pm 1.5(40-45)$ \\
& SRGB & $42.62 \pm 1.78(40.3-44.9)$ \\
Waist circumference $(\mathrm{cm})$ & SRSG & $118.70 \pm 5.98(107-131)$ \\
& SRGB & $120.58 \pm 9.76(100-140)$ \\
\hline
\end{tabular}

BMI: body mass index. SRSG: Silastic $®$ ring sleeve gastrectomy. SRGB: Silastic $®$ ring gastric bypass. *No significant difference was observed between the groups.

Table 4. Comparison of age, preoperative body mass index and preoperative waist circumference between the groups.

Considering the entire sample, BMI decreased from 42.47 to $27.5 \pm 2.67$ ( $p<0.05)$. Excess BMI loss was $86.18 \pm 15 \%$ (46.6 - 114.6). In addition, we observed a reduction in waist circumference from 119.62 to $90.38 \pm 7.9 \mathrm{~cm}(74-108)(\mathrm{p}<0.05)$. The results obtained with both surgical procedures were similar with regard to weight loss, BMI reduction, excess BMI loss and waist circumference reduction (Table 5).

\begin{tabular}{cccc}
\hline Variables & SRSG & SRGB & p \\
\hline Weight loss $(\%)$ & $-34.65(6.43)$ & $-35.32(6.20)$ & 0.751 \\
BMI loss (\%) & $-35.11(6.03)$ & $-35.35(6.22)$ & 0.893 \\
Excess BMI loss & $86.51(14.20)$ & $85.86(15.97)$ & 0.954 \\
waist circumference & & & 0.626 \\
reduction (\%) & $-23.98(5.42)$ & $-23.95(7.86)$ & 0 \\
\hline
\end{tabular}

BMI = body mass index. SRSG: Silastic ${ }^{\circledR}$ ring sleeve gastrectomy. SRGB: Silastic ${ }$ ring gastric bypass.

Table 5. Comparison of weight loss, BMI reduction, percentage of excess BMI reduction and waist circumference reduction between the groups.

Decreased fasting glucose levels were observed in the postoperative period ( $p<0.001)$, as shown in Figure 1. 


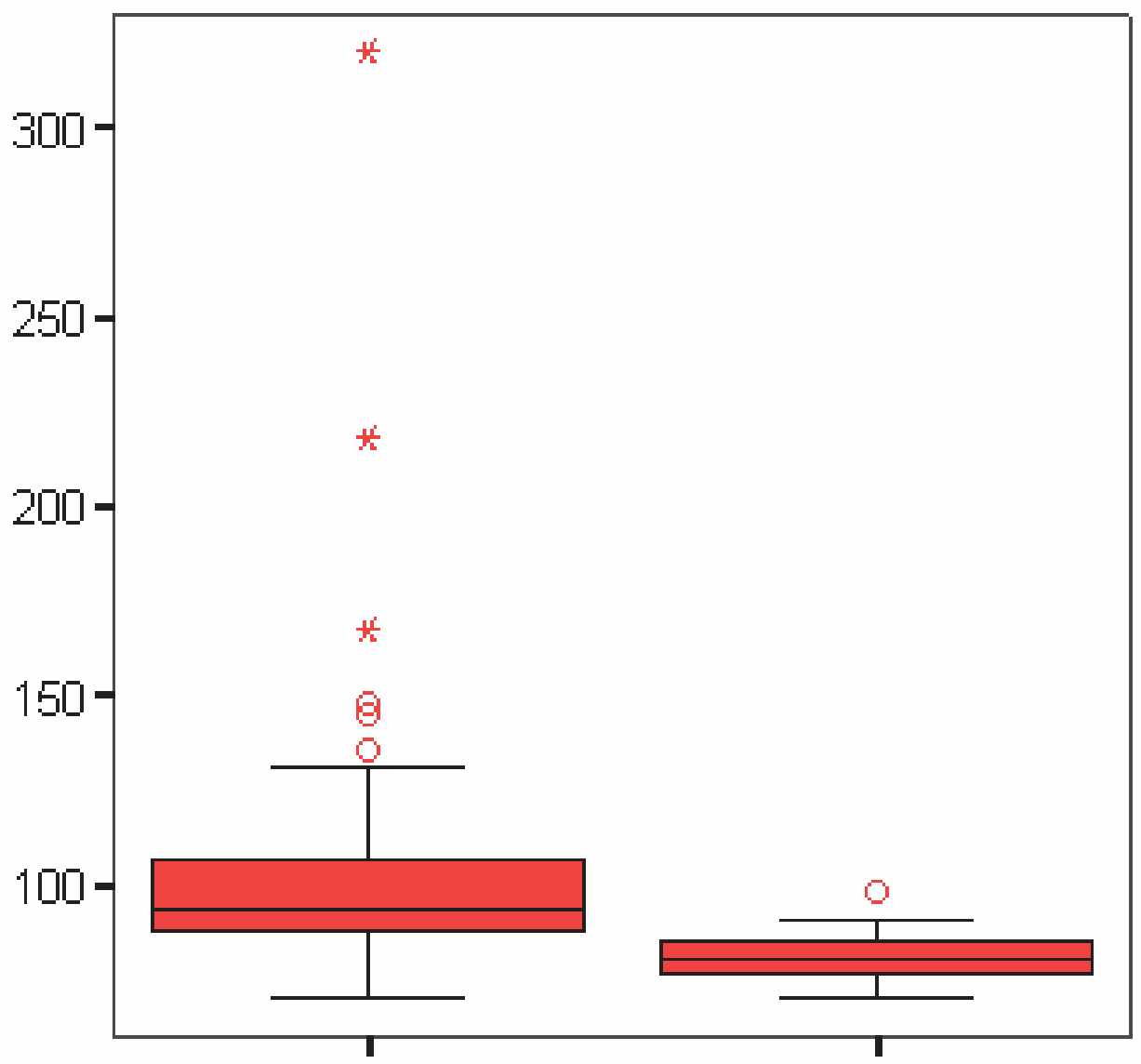

Fig. 1. Preoperative and postoperative fasting glucose levels $\mathrm{mg} / \mathrm{dl}(\mathrm{p}<0.001)$.

This decrease was similar in both groups (Table 6).

\begin{tabular}{ccc}
\hline Group $^{*}$ & Period $^{* *}$ & Fasting glucose levels \\
\hline \multirow{2}{*}{ SRSG } & Preoperative & $108.5 \pm 43.76(75-320)$ \\
& Postoperative & $80.79 \pm 6.47(71-98)$ \\
\multirow{2}{*}{ SRGB } & Preoperative & $98.25 \pm 27.18(70-218)$ \\
& Postoperative & $81.04 \pm 5.22(70-91)$ \\
\hline
\end{tabular}

SRSG: Silastic $®$ ring sleeve gastrectomy. SRGB: Silastic ${ }^{\circledR}$ ring gastric bypass. *No significant difference was observed between groups. ${ }^{* *} \mathrm{p}<0.001$.

Table 6. Preoperative and postoperative fasting glucose levels for both groups.

Both surgical procedures proved effective in promoting the resolution of T2DM and GI in the affected patients ( $<<0.001)$, as shown in Table 7 . 


\begin{tabular}{cccc}
\hline & \multicolumn{2}{c}{ Preoperative T2DM and GI } & \multirow{2}{*}{ Total } \\
\cline { 2 - 3 } Preoperative T2DM and GI & Absent & Present & \\
\hline Absent & 37 & 0 & 37 \\
\cline { 2 - 3 } Present & $60 \%$ & $0 \%$ & $60 \%$ \\
Total & 25 & 0 & 25 \\
& $40 \%$ & $0 \%$ & $40 \%$ \\
\hline
\end{tabular}

T2DM: type 2 diabetes mellitus. GI: glucose intolerance. Groups vs. time, $\mathrm{p}<0.001$.

Table 7. Remission of type 2 diabetes mellitus and glucose intolerance in the patients affected submitted to surgery.

All of the patients were able to discontinue the use of oral hypoglycemic agents or insulin, or both, during the follow-up period (Figure 2).

\begin{tabular}{|c|c|c|c|c|}
\hline \multicolumn{2}{|c|}{ Glucose homeostasis box } & \multicolumn{2}{|c|}{ Preoperative } & \multicolumn{2}{c|}{ Postoperative } \\
\cline { 2 - 4 } & $\mathbf{n}$ & $\%$ & $\mathbf{n}$ & $\%$ \\
\hline Normal & 39 & $60 \%$ & 62 & $100 \%$ \\
Glucose intolerance & 12 & $18 \%$ & 0 & $0 \%$ \\
T2DM - diet & 6 & $9 \%$ & 0 & $0 \%$ \\
Oral hypoglycemic agents & 7 & $11 \%$ & 0 & $0 \%$ \\
\hline Oral hypoglycemic agents + Insulin & 1 & $2 \%$ & 0 & $0 \%$ \\
\hline \hline Total & 65 & $100 \%$ & 62 & $100 \%$ \\
\hline
\end{tabular}

Fig. 2. Progress of glucose homeostasis and treatment of the patients submitted to surgery.

Although it was not the main focus of the present study, it was noteworthy that a fistula was developed at the staple line in two $(6 \%)$ SRSG group patients $(p=0.4936)$. Both patients required reoperation. One of these patients died and the other was submitted to total gastrectomy, which led to the resolution of the fistula. 


\subsection{Discussion}

The SG procedure has been increasingly used in bariatric surgery.12-17 However, there are few prospective clinical studies in the literature that compare that emerging procedure with the gold standard. ${ }^{12,17}$

In the present study, SG was performed and a Silastic ${ }^{\circledR}$ ring was placed around the stomach. We obtained a small, functional stomach, like that obtained with traditional vertical gastroplasty, and removed the principal site of ghrelin production, which gave the SRSG the characteristics of both bariatric and endocrine surgery. ${ }^{19}$ The removal of the principal site of ghrelin production led to a decrease in ghrelin levels, adding a hormonal element to SRSG, which other restrictive procedures such as adjustable gastric banding lack. ${ }^{31}$ Some authors have reported the use of added restriction in SG in order to increase the intensity and duration of weight loss $19,37,38$. In addition, by placing a Silastic ${ }^{\circledR}$ ring around the stomach in all patients of our sample, both procedures became identical at the portion located above the ring.

Gastric bypass is the most used procedure in bariatric surgery and is considered by many the gold standard. Some researchers have reported that SG is less risky than RYGB.12-14 However, in our sample, the most serious complications occurred in the SRSG group, which is, albeit not statistically significant, noteworthy.

Weight loss, BMI reduction, waist circumference reduction and excess BMI loss were expressive and similar in both groups. These findings are in accordance with those of some studies, $12,15,17$ but in disagreement with those of other studies ${ }^{13,14}$ that have regarded SG as the first stage of a definitive surgery. The good results of the present study are probably due to the judicious selection of the sample, which excluded BMI greater than 45 and patients with prior stomach or bowel surgery. In such cases, the results have been admittedly less effective. Other factors that might have contributed to the results of the present study include the calibration of the remaining stomach using a 32-Fr tube and the placement of a Silastic ${ }^{\circledR}$ ring. In other studies in which weight loss was less pronounced, tubes of greater caliber were used ${ }^{39}$ and a Silastic ${ }^{\circledR}$ ring was not placed. ${ }^{13,14}$

Resolution of T2DM and decreased incidence of the disease have been well-documented in various types of bariatric surgery. ${ }^{5}$ In two studies of patients submitted to SG, control of T2DM was achieved in $80 \%$ of the cases.13,14 This remission rate was higher than that commonly reported for restrictive procedures such as vertical banded gastroplasty 5 and adjustable gastric banding; 20 it was, however, lower than that obtained with RYGB9,26 and biliopancreatic diversion procedures. ${ }^{21}$

In the study described above, the rate of clinical remission of GI and T2DM was similar for both groups of patients (100\%). The reduction in blood glucose levels was also similar for both groups, a surprising result that has been reported in another study. ${ }^{17}$ Because SRSG is basically a restrictive procedure that theoretically does not affect incretin expression, it was expected that the results obtained with this procedure would be inferior to those obtained after procedures with duodenal switch with regard to glucose homeostasis.23,24,29,30 In the present study, glucose levels might have decreased as a result of the expressive weight loss observed in both groups, which led to increased sensitivity to insulin and decreased production of leptin, followed by increased insulin secretion and remission of GI and $\mathrm{T}_{2} \mathrm{DM}^{40}$. Other hormones produced in the adipose tissue, such as resistin, might also have been involved in the glycemic control observed in the present study. ${ }^{41,42}$

We should also take into consideration that the patients submitted to surgery in the present study presented with mild GI or T2DM, the remission of which is more likely according to previous studies. 22,24 
The greatest limitation of our prospective, controlled study was the lack of randomization. This occurred because the Research Ethics Committee and the authors of this study considered that the often irreversible surgical procedures performed in the present study could not have been decided on without patient consent. A similar ethical issue was reported by the authors of the Swedish Obese Subjects study. ${ }^{5}$ In order to overcome such limitations we selected patients with rather similar characteristics. Both groups comprised patients with similar age, BMI, waist circumference and fasting glucose levels in the preoperative period. This translated to a superiority of this study over other studies conducted previously, in which the groups investigated were not similar, ${ }^{12}$ the sample was not homogeneous ${ }^{15}$ and the patients included often presented with $\mathrm{BMI}<40^{12,15,17}$ and/or $>$ $50.12-17$

The surgical procedures performed in the present study, i.e. SRSG and SRGB, resulted in marked weight loss, BMI reduction, waist circumference reduction, excess BMI loss, improved glucose homeostasis and remission of GI and T2DM. These results were similar in both groups of morbidly obese patients. Further studies should be carried out adopting a longer follow-up period, as well as investigating other variables and possible hormonal changes, in order to consolidate SRSG.

With the satisfactory results obtained in the surgical treatment of T2DM through bariatric surgery in the last few years, has been evaluated the possibility of expanding the procedure indications for patients who are in a lesser degree of overweight. Such conduct has been accepted more liberally in patients with BMI between 30 and 35, but there are several clinical studies in subjects with BMI between 25 and 30. Recently, the IDF (International Diabetes Federation) classified as eligible for metabolic surgery, T2DM patients with BMI between 30 and 35.43

An Australian study, including patients with BMI between 30 and 40, comparing the intervention adjustable gastric band vs conventional therapy had remission of T2DM in $73 \%$ of the subjects against $13 \%$ in patients who underwent conventional therapy, with improvement in glucose levels, reduction of glycated hemoglobin and decrease of insulin plasma levels, demonstrating an improvement in insulinic sensitivity, measured by HOMA IR. ${ }^{4}$

Preliminary study report using the operation called laparoscopic mini-gastric bypass, performed in patients with BMI between 25 and 30, produced the resolution of hyperglycemia in $70 \%$ of operated patients. 45

Double-blind randomized controlled trial including patients with BMI between 25 and 35 comparing the operations of gastric bypass vs sleeve gastrectomy showed remission of T2DM in both groups. However, the sleeve gastrectomy group remission occurred in $47 \%$ of patients and gastric bypass in group $93 \%$. Demonstrating the superiority of gastric bypass in individuals with less overweight, probably due to the incretin action and the activity reduction of dipeptidyl peptidase- 4.46

It should be noted in those patients with BMI between 25 and 35 the importance of a more detailed investigation in terms of T2DM pathogenesis, in order to reduce the possibility of submitting to surgery patients with complete failure of beta cells or autoimmune disease (DMT1ou LADA - Late autoimmune diabetes of adult). The preoperative evaluation of these patients should include: concentration of peptide $C$ and tests for markers of pancreatic autoimmunity, as anti-glutamic acid dearboxylase (GAD) antibody and anti- Langerhans islet antibody. 


\section{Conclusion}

The bariatric-metabolic surgery has unquestionable role in remission (cure?) of T2DM in subjects with BMI greater than 35. In this group of patients seems to be no difference in remission rates of T2DM between subjects undergoing gastric bypass or sleeve gastrectomy.

In subjects with less overweight, BMI between 30 and 35, nowadays eligible for metabolic surgery, gastric bypass seems to be more effective in producing remission of T2DM.

The metabolic surgery in patients with BMI between 25 and 30, still investigational, seems to show promising results in remission of T2DM, but further studies should be carried out to define its actual role.

\section{References}

[1] North American Association for the Study of Obesity (NAASO) and National Heart, Lung, and Blood Institute (NHLBI). The Practical Guide: Identification, Evaluation, and Treatment of Overweight and Obesity in Adults. NIH Publication \#00-4084, Oct 2000.

[2] Must A, Spadano J, Coakley EH, Field AE, Colditz G, Dietz WH. The disease burden associated with overweight and obesity. JAMA. 1999;282:1523-1529.

[3] Gomes MB, Giannella Neto D, De Mendonça E, Tambascia MA, Fonseca RM, Réa RR, et al. Prevalência de sobrepeso e obesidade em pacientes com diabetes mellitus do tipo 2 no Brasil: Estudo multicêntrico nacional. Arq Bras Endocrinol Metab 2006;50:136-44.

[4] Venkat Narayan KM, Gregg EW, Fagot-Campagna A, Engelgau MM, Vinicor F. Diabetes: a common, growing, serious, costly, and potentially preventable public health problem. Diabetes Res Clin Pract. 2000;50:S77-84.

[5] Sjöström L, Narbro K, Sjöström D, Karason K, Larsson B, Wedel H, et al. Effects of bariatric surgery on mortality in swedish obese subjects. $\mathrm{N}$ Engl J Med. 2007;357:741-52.

[6] Bose M, Oliván B, Teixeira J, Pi-Sunyer FX, Laferrère B. Do incretins play a role in the remission of type 2 diabetes after gastric bypass surgery: what are the evidence? Obes Surg. 2009;19:217-29.

[7] Christou NV, Sampalis JS, Liberman M, Look D, Auger S, McLean APH, et al. Surgery decreases long-term mortality, morbidity, and health care use in morbidly obese patients. Ann Surg. 2004;240:416-424.

[8] Adams TD, Gress RE, Smith SC, Halverson RC, Simper SC, Rosamond WD, et al. Longterm mortality after gastric bypass surgery. N Engl J Med. 2007;357:753-61.

[9] Pories WJ, Swanson MS, MacDonald KG, Long SB, Morris PG, Brown BM, et al. Who would have thought it? An operation proves to be the most effective therapy for adult-onset diabetes mellitus. Ann Surg 1995;222:339-350.

[10] Buchwald H, Buchwald JN. Evolution of operative procedures for the management of morbid obesity 1950-2000. Obes Surg. 2002;12:705-17.

[11] Fobi MA. Why the operation I prefer is silastic ring banded gastric bypass. Obes Surg. 1991;1:423-6. 
[12] Lee CM, Cirangle PT, Jossart GH. Vertical gastrectomy for morbid obesity in 216 patients: report of two-year results. Surg Endosc. 2007; 21:1810-6.

[13] Cottam D, Qureshi FG, Mattar SG, Sharma S, Holover S, Bonanomi G, et al. Laparoscopic sleeve gastrectomy as an initial weight-loss procedure for high-risk patients with morbid obesity. Surg Endosc 2006; 20:859-63.

[14] Silecchia G, Boru C, Pecchia A, Rizzelo M, Casella G, Leonetti F, et al. Effectiveness of laparoscopic sleeve gastrectomy (first stage of biliopancreatic diversion with duodenal switch) on co-morbidities in super-obese high-risk patients. Obes Surg 2006; 16:1138-44.

[15] Baltasar A, Serra C, Perez N, Bou R, Bengochea M, Ferri L. Laparoscopic sleeve gastrectomy: a multi-purpose bariatric operation. Obes Surg 2005; 15(8):1124-8.

[16] Moon Han S, Kim WW, Oh JH. Results of laparoscopic sleeve gastrectomy (LSG) at 1 year in morbidly obese Korean patients. Obes Surg 2005;15:1469-75.

[17] Vidal J, Ibarzabal A, Romero F, Delgado S, Momblán D, Flores L, et al. Type 2 diabetes mellitus and the metabolic syndrome following sleeve gastrecmomy in severely obese subjects. Obes Surg. 2008; 18:1077-82.

[18] Valezi AC, Brito EM, Souza JCL, Guariente ALM, Emori FT, Lopes VCH. A importância do anel de silicone na derivação gástrica em Y de Roux para o tratamento da obesidade. Rev Col Bras Cir. 2008; 35:18-22.

[19] Miguel GPS, Azevedo JLMC, Gicovate Neto C, Moreira CLCB, Viana EC, Carvalho PS. Glucose homeostasis and weight loss in morbidly obese patients undergoing banded sleeve gastrectomy: a prospective clinical study. Clinics 2009; 64: 1093-8.

[20] Dixon JB, O’Brien PE, Playfair J, Chapman L, Schachter LM, Skinner S, et al. Adjustable gastric banding and conventional therapy for the type 2 diabetes: a randomized controlled trial. JAMA. 2008;299:316-23.

[21] Scopinaro N, Adami GF, Marinari GM, Gianetta E, Traverso E, Friedman, et al. Biliopancreatic diversion. World J Surg. 1998;22:936-946.

[22] Schauer PR, Burguera B, Ikramuddin S, Cottam D, Gourash W, Hamad G, et al. Effect of laparoscopic Roux-en Y gastric bypass on type 2 diabetes mellitus. Ann Surg. 2003;238(4):467-485.

[23] Cummings DE, Overduin J, Foster-Schubert KE. Gastric bypass for obesity: mechanisms of weight loss and diabetes resolution. J Clin Endocrinol Metab. 2004;89:2608-2615.

[24] Rubino F, Forgione A, Cummings DE, Vix M, Gnuli D, Mingrone G, et al. The mechanism of diabetes control after gastrointestinal bypass surgery reveals a role of the proximal small intestine in the pathophysiology of type 2 diabetes. Ann Surg 2006;244:741-749.

[25] Buchwald H, Avidor Y, Braunwald E, Jensen MD, Pories W, Fahrbach K, et al. Bariatric surgery: a systematic review and meta-analysis. JAMA. 2004;292:17241737.

[26] Carvalho PS, Barelli MC, Moreira CLCB, Oliveira FH, Guzzo MF, Miguel GPS, et al. Can bariatric surgery cure metabolic syndrome? Arq Bras Endocrinol e Metab 2007;51(1):79-85. 
[27] Cavaghan MK, Ehrmann DA, Polonsky KS. Interactions between insulin resistance and insulin secretion in the development of glucose intolerance. J Clin Invest. 2000;106(6):329-33.

[28] Wajchenberg BL. Beta-cell failure in diabetes and preservation by clinical treatment. Endocr Rev. 2007;28:187-218.

[29] Mason EE. The mechanism of surgical treatment of type 2 diabetes. Obes Surg. 2005;15:459-461.

[30] Martins MVD, Souza AAP. Mecanismos cirúrgicos de controle do diabetes mellitus tipo 2 após cirurgia bariátrica. Rev Col Bras Cir. 2007;34(5):343-346.

[31] Langer FB, Reza Hoda MA, Bohdjalian A, Felberbauer FX, Zacherl J, Wenzl E, et al. Sleeve gastrectomy and gastric banding: effects on plasma ghrelin levels. Obes Surg 2005; 15(7):1024-9.

[32] Nakazato M, Murakami N, Date $Y$, Kojima M, Matsuo H, Kangawa K, et al. A role for ghrelin in the central regulation of feeding. Nature. 2001;409:194-8.

[33] Pories WJ, Albrecht RJ. Etiology of type II diabetes mellitus: role of the foregut. World J Surg. 2001;25:527-531.

[34] Drucker DJ. Biological actions and therapeutic potential of the glucagon-like peptides. Gastroenterology. 2002;122:531-544.

[35] Sociedade Brasileira de Diabetes. Diretrizes: tratamento e acompanhamento do diabetes mellitus. 2007. Diagraphic editora.

[36] Deitel M, Gawdat K, Melissas J. Reporting weight loss 2007. Obes Surg. 2007; 17:565-568.

[37] Cai J, Zheng C, Xu L, Chen D, Li X, Wu J, et al. Therapeutic effects of sleeve gastrectomy plus gastric remnant banding on weigth reduction and gastric dilatation: na animal study. Obes Surg. 2008;18:1411-7.

[38] Greenstein AJ, Vine AJ, Jacob BP. When sleeve gastrectomy fails: adding a laparoscopic adjustable gastric band to increase restriction. Surg Endosc. 2009 Epub ahead of print.

[39] Braghetto I, Korn O, Valladares H, Gutiérrez L, Csendes A, Debandi A, et al. Laparoscopic sleeve gastrectomy: surgical technique, indications and clinical results. Obes Surg. 2007;17:1442-50.

[40] Meirelles K, Ahmed T, Culnan DM, Lynch CJ, Lang CH, Cooney R. Mechanisms of glucose homeostasis after Roux-en-Y gastric bypass surgery in the obese, insulinresistant Zucker rat. Ann Surg. 2009;249:277-85.

[41] Diamond F. The endocrine function of adipose tissue. Growth: genetics \& hormones 2002; 18:17-22.

[42] Steppan CM, Bailey ST, Bhat S, Brown EJ, Banerjee RR, Wrigt CM, et al. The hormone resistin links obesity to diabetes. Nature. 2001; 409:307-312.

[43] Available in:<http://www.idf.org/press-release/idf-announces-new-positionsupporting-surgery-treat-type-2-diabetes> Accessed on May 2, 2011.

[44] Dixon JB, O'Brien PE, Playfair J, Chapman L, Schachter LM, Skinner S, Proietto J, Bailey M, Anderson M. Adjustable gastric banding and conventional therapy for type 2 diabetes: a randomized controlled trial. JAMA. 2008 Jan 23;299(3):316-323. 
[45] Kim Z, Hur KY. Laparoscopic mini-gastric bypass for type 2 diabetes: the preliminary report. World J Surg. 2011 Mar;35(3):631-636.

[46] Lee WJ, Chong K, Ser KH, Lee YC, Chen SC, Chen JC, Tsai MH, Chuang LM. Gastric bypass vs sleeve gastrectomy for type 2 diabetes mellitus: a randomized controlled trial. Arch Surg. 2011 Feb;146(2):143-148. 


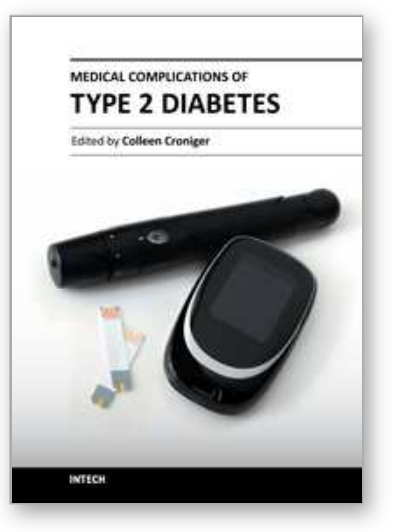

\author{
Medical Complications of Type 2 Diabetes \\ Edited by Dr. Colleen Croniger
}

ISBN 978-953-307-363-7

Hard cover, 412 pages

Publisher InTech

Published online 12, September, 2011

Published in print edition September, 2011

Obesity and type 2 diabetes are increasing worldwide problems. In this book we reviewed insulin secretion in both healthy individuals and in patients with type 2 diabetes. Because of the risk associated with progression from insulin resistance to diabetes and cardiovascular complications increases along a continuum, we included several chapters on the damage of endothelial cells in type 2 diabetes and genetic influences on endothelial cell dysfunction. Cardiovascular complications occur at a much lower glucose levels, thus a review on the oral glucose tolerance test compared to other methods was included. The medical conditions associated with type 2 diabetes such as pancreatic cancer, sarcopenia and sleep disordered breathing with diabetes were also discussed. The book concludes with several chapters on the treatments for this disease offering us hope in prevention and successful alleviation of the co-morbidities associated with obesity and type 2 diabetes.

\title{
How to reference
}

In order to correctly reference this scholarly work, feel free to copy and paste the following:

Gustavo P. S. Miguel, Perseu Carvalho, João Luiz Azevedo, Murilo Hosken Júnior, Evelyn Zambrana, Otávio Azevedo and Isaac Abreu (2011). Can Bariatric or Metabolic Surgery Cure Type 2 Diabetes?, Medical Complications of Type 2 Diabetes, Dr. Colleen Croniger (Ed.), ISBN: 978-953-307-363-7, InTech, Available from: http://www.intechopen.com/books/medical-complications-of-type-2-diabetes/can-bariatric-or-metabolicsurgery-cure-type-2-diabetes-

\section{INTECH}

open science | open minds

\section{InTech Europe}

University Campus STeP Ri

Slavka Krautzeka 83/A

51000 Rijeka, Croatia

Phone: +385 (51) 770447

Fax: +385 (51) 686166

www.intechopen.com

\section{InTech China}

Unit 405, Office Block, Hotel Equatorial Shanghai

No.65, Yan An Road (West), Shanghai, 200040, China 中国上海市延安西路65号上海国际贵都大饭店办公楼 405 单元

Phone: +86-21-62489820

Fax: $+86-21-62489821$ 
(C) 2011 The Author(s). Licensee IntechOpen. This chapter is distributed under the terms of the Creative Commons Attribution-NonCommercialShareAlike-3.0 License, which permits use, distribution and reproduction for non-commercial purposes, provided the original is properly cited and derivative works building on this content are distributed under the same license. 